\title{
ANALISIS KESEHATAN DAN KESELAMATAN KERJA (K3) DENGAN METODE HAZARD AND OPERABILITY STUDY (HAZOP)
}

\author{
Choirul Anwar, ${ }^{1, a}$, Willy Tambunan ${ }^{2, b}$, Suwardana Gunawan ${ }^{3, c}$ \\ 1 Jurusan Teknik Industri Fakultas Teknik Universitas Mulawarman \\ ${ }^{2}$ Lembaga Penelitian Universitas Mulawarman \\ aanwarik0145@gmail.com, ’willytambunan@ft.unmul.ac.id, cgunawansuwardi@gmail.com
}

\begin{abstract}
Abstrak.
Pada era industri saat ini banyak sekali kemajuan dari teknologi mesin ataupun metodemetode yang digunakan oleh perusahaan dalam sistem produksinya. Agar sistem produksi dan produktifitas pada perusahaan berlangsung dengan efektif, aman, dan efisien. Salah satu untuk mewujudkan hal tersebut ialah dengan memperhatikan kesehatan dan keselamatan kerja (K3) karyawan yang ada pada peruahaan. Identifikasi kecelakaan kerja yang digunakan dalam penelitian ini menggunakan metode Hazard and Operability Study (HAZOP). Dalam sistem pekerjaan yang ada pada PDAM terdapat pekerjaan yang rentan akan terjadinya kecelakaan kerja seperti pada bidang maintenance atau perawatan pada mesin, sistem produksi pengolahan air, dan pekerjaan yang dilakukan di workshop. Dari hasil observasi lapangan pada workshop PDAM Tirta Kencana dan wawancara pada pekerja, terdapat 50 potensi bahaya atau hazard yang ada di workshop PDAM Tirta Kencana kemudian digolongkan berdasarkan jenis sumbernya menjadi 12 sumber bahaya atau hazard. Terdapat 3 tingkatan risiko kecelakaan kerja dari sumber hazard yang didapat dari hasil penilaian risk matrix, yang berpotensi menimbulkan kecelakaan kerja. Tingkatan risiko tersebut adalah risiko ekstrim sebanyak 1 sumber hazard, risiko tinggi sebanyak 5 sumber hazard, dan risiko sedang sebanyak 6 sumber hazard. Usulan dari hasil penelitian ini adalah melakukan pelatihan $\mathrm{K} 3$, melakukan pengawasan kerja, dan melakukan perawatan pada mesin dan peralatan.
\end{abstract}

Kata kunci. Kesehatan dan Keselamatan Kerja (K3), Hazard and Operability Study (HAZOP), Hazard, Risk Matrix, Likelihood, Severity.

\section{Abstract.}

In the current industrial era a lot of progress from machine technology or methods used by companies in their production systems. So that the system of production and productivity in the company takes place effectively, safely, and efficiently. One way to achieve this is by paying attention to the occupational health and safety (K3) of the employees in the company. The identification of work accidents used in this study uses the Hazard and Operability Study (HAZOP) method. In the work system in the PDAM there is work that is vulnerable to work accidents such as in the field of maintenance or maintenance on machinery, water treatment production systems, and work carried out in the workshop. From the results of field observations at the PDAM Tirta Kencana workshop and interviews with workers, there were 50 potential hazards that existed at the PDAM Tirta Kencana workshop and were then classified according to the type of sources into 12 sources of hazards. There are 3 levels of work accident risk from hazard sources obtained from the risk matrix assessment, which has the potential to cause work accidents. The level of risk is an extreme risk of 1 source of hazard, a high risk of 5 sources of hazard, and a moderate risk of 6 
sources of hazard. The proposal of the results of this study is to conduct OSH training, conduct work supervision, and perform maintenance on machinery and equipment.

Keywords. Occupational Health and Safety (K3), Hazard and Operability Study (HAZOP), Hazard, Risk Matrix, Likelihood, Severity.

\section{PENDAHULUAN}

Perindustrian terus berkembang sampai pada detik ini. Seiring dengan kemajuan industri, kecelakaan kerja pun mengiringinya. Hal tersebut terjadi karena manusia semakin banyak berinteraksi dengan peralatan baru, kondisi baru, produk dan lainnya yang merupakan hazard. Hazard merupakan sumber atau kondisi yang mempunyai potensi untuk menimbulkan kecelakaan, penyakit, kerusakan properti, kerusakan lingkungan atau kombinasi dari hal tersebut. Risiko merupakan kemungkinan terjadinya sesuatu yang akan memberikan dampak yang mempengaruhi tujuan. Untuk itu diperlukan suatu manajemen agar dapat mengatur jalannya kegiatan dengan baik, termasuk pula manajemen risiko K3 (Kesehatan dan Keselamatan Kerja) karena hal tersebut juga merupakan bagian dari perencanaan dan pengendalian suatu pekerjaan.

Perusahaan Daerah Air Minum atau PDAM Tirta Kencana yang berada di daerah Samarinda, Kalimantan Timur adalah perusahaan yang bergerak pada bidang pelayanan masyarakat Samarinda untuk pemenuhan kebutuhan air bersih. Dalam sistem pekerjaan yang ada pada PDAM terdapat pekerjaan yang rentan akan terjadinya kecelakaan kerja seperti pada bidang maitenance atau perawatan pada mesin, sistem produksi pengolahan air, dan pekerjaan yang dilakukan di workshop. Penelitian berfokus pada pekerjaan yang dilakukan di workshop PT. PDAM Tirta Kencana karena risiko kecelakaan kerja lebih besar terjadinya. Jenis pekerjaan yang ada di workshop seperti pengelasan, pembubutan, pemotongan dengan gerinda, penggunaan alat brander, dan penggunaan alat bor. Kecelakaan kerja yang mungkin terjadi pada pekerja tersebut seperti tertimpa, terbentur, terbakar, terpotong, terjatuh dan kecelakaan kerja yang lainnya.

Terdapat banyak metode dalam menganalisis kecelakaan kerja, seperti metode Hazard Identification, Risk Assessment, dan Risk Control (HIRARC), Hazard Identification and Risk Assesment (HIRA), Hazard Identification (HAZID), dan Hazard and Operability Study (HAZOP). Tujuan penggunaan HAZOP dalam penelitian ini adalah untuk meninjau suatu proses atau operasi pada suatu sistem secara sistematis, untuk menentukan apakah proses penyimpangan dapat mendorong kearah kejadian atau kecelakaan yang tidak diinginkan. HAZOP itu sendiri secara sistematis bekerja dengan mencari berbagai faktor penyebab (cause) yang memungkinkan timbulnya kecelakaan kerja dan menentukan konsekuensi yang merugikan sebagai akibat terjadinya penyimpangan serta memberikan rekomendasi atau tindakan yang dapat dilakukan untuk mengurangi dampak dari potensi risiko yang telah diidentifikasi (Munawir, 2010). 


\section{Studi Pustaka}

Kesehatan kerja adalah promosi dan pemeliharaan dari derajat kesehatan yang terdiri dari kesehatan fisik, mental dan sosial dari tenaga kerja dalam semua pekerjaannya melalui pencegahan penyakit, pengontrolan risiko $\mathrm{K} 3$, penyesuaian pekerjaan terhadap tenaga kerja dan adaptasi tenaga kerja terhadap pekerjaan (Ramdan, 2006).

Kecelakaan kerja merupakan kecelakaan yang terjadi berhubungan dengan kerja, termasuk penyakit yang timbul karena hubungan kerja, demikian pula kecelakaan yang terjadi dalam perjalanan ke dan dari tempat kerja.

Hazard atau bahaya dapat didefinisikan sebagai keadaan yang menimbulkan atau meningkatkan terjadinya chance of loss (kemungkinan kerugian) dari suatu bencana tertentu. Jadi, hal-hal seperti kecerobohan pemeliharaan rumah yang buruk, jalan raya jelek, mesin yang tidak terpelihara, dan pekerjaan yang berbahaya adalah hazard dan keadaan tersebut yang meningkatkan kemungkinan kerugian (Darmawi, 2016).

The Hazard and Operability Study (HAZOP) adalah standar teknik analisis bahaya yang digunakan dalam persiapan penetapan keamanan dalam suatu sistem atau modifikasi untuk suatu keberadaan potensi bahaya atau masalah operability nya. HAZOP adalah suatu metode identifikasi bahaya yang sistematis teliti dan terstruktur untuk mengidentifikasi berbagai permasalahan yang menganggu jalanya proses dan risiko yang terdapat pada suatu peralatan yang dapat menimbulkan risiko merugikan bagi manusia/ fasilitas pada sistem. Dengan kata lain metode ini digunakan sebagai upaya pencegahan sehingga proses yang berlangsung dalam suatu sistem dapat berjalan lancar dan aman (Juliana, 2008).

Dasar penilaian risiko dan pengendaliannya (risk assessment and control) dalam prosedur yang ditetapkan oleh UNSW adalah sebagai berikut (UNSW Health and Safety, 2008) :

a. Identifikasi aktivitas.

b. Identifikasi siapa yang mungkin akan terkena risiko pada aktivitas tertentu.

c. Identifikasi bahaya.

d. Identifikasi risiko yang terkait.

e. Memberi nilai pada risiko dengan control yang ada.

f. Mengidentifikasi control tambahan yang sesuai.

g. Menilai ulang risiko.

h. Membuat semua daftar prosedur keadaan darurat yang berhubungan dengan aktivitas tertentu.

i. Melaksanakan pengendalian risiko.

j. Membuat daftar dokumen legislative yang terkait dengan penilaian risiko.

k. Otorisasi penilaian risiko.

1. Menandatangani penilaian risiko.

m. Mengamati kontrol yang telah dilakukan.

\section{METODOLOGI PENELITIAN}

Pengumpulan data dalam penelitian ini mencakup data primer dan data sekunder.Data primer merupakan data penelitian yang didapatkan dengan melihat langsung kondisi lapangan. Cara 
pengumpulan data primer ini dilakukan dengan observasi, pengumpulan data secara observasi adalah teknik pengumpulan data dengan cara peninjauan secara langsung kelokasi perusahaan dengan memperhatikan proses kerja perusahaan dan melihat beberapa risiko yang mungkin menimbulkan risiko terhadap keselamatan pekerja dan wawancara kepada penangggung jawab perusahaan guna mendapatkan gambaran umum mengenai data yang dibutuhkan. Data sekunder berupa data yang diperoleh dari PT. PDAM Tirta Kencana seperti profil perusahaan, dan keadaan workshop. Adapun tahap-tahap penelitian yang dilakukan pada penelitian ini sebagai berikut :

a. Survei pendahuluan, bertujuan untuk melihat gambaran dan kondisi yang sebenarnya pada workshop PT. PDAM Tirta Kencana. Dengan melihat kondisi yang sebenarnya pada workshop PT. PDAM Tirta Kencana maka akan memudahkan untuk mengangkat studi kasus yang ada. Hal pertama yang dilakukan pada survei pendahuluan ini adalah dengan melakukan sebuah wawancara kepada penanggung jawab workshop tentang masalah Keselamatan dan Kesehatan Kerja (K3).

b. Studi literatur, dimaksudkan untuk mempermudah dalam mempelajari teori dan ilmu pengetahuan yang relevan dengan konsentrasi masalah yang ada. Studi literatur ini didapatkan baik dalam buku, kumpulan Tugas Akhir, Jurnal, maupun akses internet.

c. Identifikasi masalah, berfungsi sebagai pencari titik-titik tertentu yang menjadi pusat atau penyebab dari timbulnya hazard (bahaya) yang menyebabkan kecelakaan kerja pada workshop PT. PDAM Tirta Kencana.

d. Perumusan masalah, berupa identifikasi bahaya yang terdapat pada kondisi yang sebenarnya.

e.Tujuan penelitian, berisikan hasil akhir yang diharapkan dapat terselesaikan setelah pengerjaan laporan penelitian ini. Tujuan penelitian ini memiliki dasar yang mampu menyelaraskan dengan latar belakang dan perumusan masalah.

Langkah-langkah yang dilakukan pada tahapan pengumpulan dan pengolahan data pada penilitian adalah sebagai berikut :

a. Mengetahui urutan proses.

b. Mengidentifikasi adanya potensi bahaya.

c. Melengkapi kriteria yang ada pada HAZOP worksheet dengan urutan sebagai berikut:

1) Mengklasifikasikan potensi bahaya yang ditemukan (sumber potensi bahaya dan frekuensi temuan potensi bahaya).

2) Mendeskripsikan deviation atau penyimpangan yang terjadi selama proses operasi.

3) Mendeskripsikan penyebab terjadinya (cause).

4) Mendeskripsikan yang dapat ditimbulkan dari penyimpangan tersebut (consequences).

5) Menentukan action atau tindakan sementara yang dapat dilakukan.

6) Menilai risiko (risk asessment) yang timbul dengan mendefinisikan kriteria

Likelihood dan Consequences (severity).

Kriteria likelihood yang digunakan adalah frekuensi dimana dalam perhitungannya secara kuantitatif berdasarkan data perusahaan selama pada tahun 2018. Kriteria consequences (severity) yang digunakan adalah akibat yang akan diterima pekerja yang didefinisikan secara kualitatif dan mempertimbangkan hari kerja yang hilang.

d. Melakukan perangkingan dari potensi bahaya yang telah diidentifikasi menggunakan worksheet HAZOP dengan memperhitungkan likelihood dan consequences, kemudian menggunakan risk matrix untuk mengetahui prioritas potensi bahaya yang harus diberi prioritas untuk diperbaiki. 
e. Analisis dan pembahasan, dengan menjabarkan sumber-sumber dan akar penyebab dari permasalahan yang mengakibatkan kecelakaan kerja maupun ganggun proses itu terjadi. Adapun langkah-langkah dalam analisis dan pembahasan ini adalah:

1) Melakukan analisis terhadap akar penyebab terjadinya kecelakaan kerja maupun gangguan proses kerja yang terjadi.

2) Melakukan analisis penilaian risiko sehingga diperoleh rekomendasi perbaikan yang sesuai bahkan dapat diterapkan pada objek penelitian tersebut.

f. Rekomendasi dan Rancangan Perbaikan, dilakukan dengan perancangan perbaikan proses yang didapati pada titik-titik tertentu yang dapat menimbulkan bahaya kecelakaan kerja pada workshop PT. PDAM Tirta Kencana untuk mengurangi bahkan menghilangkan bahaya tersebut.

g. Kesimpulan dan Saran, untuk menemukan jawaban dari semua permasalahan yang diangkat dalam penelitian ini. Berdasarkan dengan hasil pengambilan kesimpulan maka dapat diberikan saran ataupun beberapa masukan usulan perbaikan dalam upaya meningkatkan kinerja dan produktifitas perusahaan.

\section{HASIL, PEMBAHASAN DAN ANALISA}

Untuk mengidentifikasi potensi bahaya apa saja yang terdapat sumber bahaya atau hazard yang ditemukan pada proses pekerjaan di workshop atau bengkel PDAM Tierta Kencana Unit 1 Cendana. Klasifikasi data sumber hazard dilakukan dengan cara mengetahui kriteria likelihood dan severity/consequences dari setiap sumber hazard yang ditemukan. Likelihood (L) adalah kemungkinan terjadinya kecelakaan kerja ketika terpapar dengan bahaya. Sedangkan severity/consequences (C) adalah tingkat yang menunjukkan keparahan cidera dan kehilangan hari kerja. Kriteria likelihood dan severity/consequences dapat dilihat pada tabel 1 dan tabel 2 sebagai berikut :

Tabel 1. Kriteria Likelihood

\begin{tabular}{|c|c|c|c|}
\hline \multicolumn{2}{|c|}{ Likelihood } \\
\hline \multirow{2}{*}{ level } & Criteria & \multicolumn{2}{|c|}{ Description } \\
\cline { 3 - 5 } & Jarang terjadi & $\begin{array}{c}\text { Kapalitatif } \\
\text { Kuantitatif } \\
\text { saat keadaan yang ekstrim }\end{array}$ & $\begin{array}{c}\text { Kurang dari 1 } \\
\text { kali per 10 tahun }\end{array}$ \\
\hline 2 & $\begin{array}{c}\text { Kemungkinan } \\
\text { kecil }\end{array}$ & $\begin{array}{c}\text { Belum terjadi tetapi bisa muncul / } \\
\text { terjadi pada suatu waktu }\end{array}$ & $\begin{array}{c}\text { Terjadi 1 kali per } \\
10 \text { tahun }\end{array}$ \\
\hline 3 & Mungkin & $\begin{array}{c}\text { Seharusnya terjadi dan mungkin } \\
\text { telah terjadi / muncul disini atau di } \\
\text { tempat lain }\end{array}$ & $\begin{array}{c}1 \text { kali per 5 } \\
\text { tahun sampai 1 } \\
\text { kali per tahun }\end{array}$ \\
\hline 4 & Kemungkinan & $\begin{array}{c}\text { Dapat terjadi dengan mudah, } \\
\text { mungkin muncul dalam keadaan } \\
\text { yang paling banyak terjadi }\end{array}$ & $\begin{array}{c}\text { Lebih dari 1 kali } \\
\text { per tahun hingga } \\
1 \text { kali perbulan }\end{array}$ \\
\hline 5 & Hampir pasti & $\begin{array}{c}\text { Sering terjadi, diharapkan muncul } \\
\text { dalam keadaan yang paling } \\
\text { banyak terjadi }\end{array}$ & $\begin{array}{c}\text { Lebih dari 1 kali } \\
\text { per bulan }\end{array}$ \\
\hline
\end{tabular}

Sumber : UNSW Health and Safety (2008) 
Tabel 2. Kriteria Consequences / Severity

\begin{tabular}{|c|c|c|c|}
\hline \multicolumn{5}{|c|}{ Consequences/ Severity } \\
\hline 1 & $\begin{array}{c}\text { Tidak } \\
\text { signifikan }\end{array}$ & $\begin{array}{c}\text { Kejadian tidak menimbulkan } \\
\text { kerugian atau cedera pada } \\
\text { manusia }\end{array}$ & $\begin{array}{c}\text { Tidak menyebabkan } \\
\text { kehilangan hari kerja }\end{array}$ \\
\hline 2 & Kecil & $\begin{array}{c}\text { Menimbulkan cedera ringan } \\
\text { kerugian kecildan tidak } \\
\text { menimbulkan dampak serius } \\
\text { terhadap kelangsungan } \\
\text { bisnis }\end{array}$ & $\begin{array}{c}\text { Masih dapat bekerja } \\
\text { pada hari / shift } \\
\text { yang sama }\end{array}$ \\
\hline 3 & Sedang & $\begin{array}{c}\text { Cedera berat dan dirawat } \\
\text { dirumah sakit, tidak } \\
\text { menimbulkan cacat tetap, } \\
\text { kerugian finansial sedang }\end{array}$ & $\begin{array}{c}\text { Kehilangan hari } \\
\text { kerja dibawah 3 hari }\end{array}$ \\
\hline 4 & Berat & $\begin{array}{c}\text { Menimbulkan cedera parah } \\
\text { dan cacat tetap dan kerugian } \\
\text { finansial besar serta } \\
\text { menimbulkan dampak serius } \\
\text { terhadap kelangsungan } \\
\text { usaha }\end{array}$ & $\begin{array}{c}\text { Kehilangan hari } \\
\text { kerja 3 hari atau } \\
\text { lebih }\end{array}$ \\
\hline 5 & Bencana & $\begin{array}{c}\text { Mengakibatkan korban } \\
\text { meninggal dan kerugian } \\
\text { parah bahkan dapat } \\
\text { menghentikan kegiatan } \\
\text { usaha selamanya }\end{array}$ & $\begin{array}{c}\text { Kehilangan hari } \\
\text { kerja selamanya }\end{array}$ \\
\hline
\end{tabular}

Sumber : UNSW Health and Safety (2008)

Setelah menentukan nilai likelihood dan consequences dari masing-masing sumber potensi bahaya, maka langkah selanjutnya adalah mengalikan nilai likelihood dan consequences sehingga diperoleh tingkat bahaya (risk level) pada risk matrix yang mana nantinya akan digunakan dalam melakukan perangkingan terhadap sumber potensi bahaya yang akan dijadikan acuan sebagai rekomendasi perbaikan apa yang sesuai dengan permasalahan yang ada. Penilaian risiko itu sendiri dilakukan dengan menggunakan risk matrix seperti pada gambar 1:
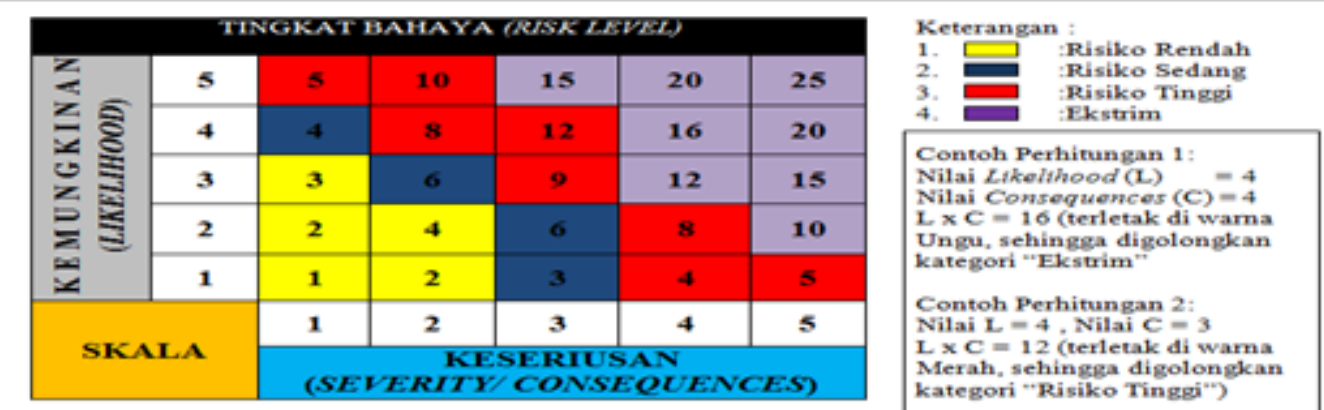

Gambar 1. Risk matrix 
Observasi dan wawancara yang dilakukan pada workshop PT. PDAM Tirta Kencana. Terdapat beberapa potensi bahaya seperti tangan tergores benda tajam, terkena percikan benda panas, terbentur, dan terkena sengatan listrik. Dari hasil observasi lapangan pada workshop PT. PDAM Tirta Kencana kemudian digolongkan berdasarkan jenis sumbernya menjadi 12 sumber bahaya atau hazard antara lain sikap pekerja, kondisi lantai, hoistcrane, brander oxy acetylene, pengelasan, pembubutan, alat gerinda (hand grinding), mesin gerinda, alat bor (hand bor), mesin bor, jigsaw, dan panel seperti yang dapat dilihat pada tabel 3 seperti berikut :

Tabel 3. Nilai kriteria sumber hazard

\begin{tabular}{|c|c|c|c|}
\hline \multirow{2}{*}{ No } & \multirow{2}{*}{ Sumber hazard } & \multicolumn{2}{|c|}{ Level kriteria } \\
\cline { 3 - 4 } & & Likelihood (L) & Consequences (C) \\
\hline 1 & Sikap pekerja & 5 & 4 \\
\hline 2 & Kondisi lantai & 3 & 2 \\
\hline 3 & Pengelasan & 3 & 3 \\
\hline 4 & Brander oxy acetylene & 3 & 4 \\
\hline 5 & Pembubutan & 3 & 3 \\
\hline 6 & Gerinda (hand grinding) & 2 & 3 \\
\hline 7 & Mesin gerinda & 2 & 3 \\
\hline 8 & Jigsaw & 2 & 3 \\
\hline 9 & Hoistcrane & 2 & 4 \\
\hline 10 & Mesin bor & 2 & 3 \\
\hline 11 & Bor (hand bor) & 2 & 3 \\
\hline 12 & Panel & 1 & 4 \\
\hline
\end{tabular}

Pengolahan data dilakukan dengan cara melakukan klasifikasi terlebih dahulu terhadap setiap sumber bahaya atau hazard yang ditemukan pada proses pekerjaan di workshop atau bengkel PDAM Tierta Kencana Unit 1 Cendana. Klasifikasi data sumber hazard dilakukan dengan cara mengetahui kriteria likelihood dan severity/consequences dari setiap sumber hazard. Dapat dilhat pada tabel 4. Sebagai berikut :

Tabel 4. Perangkingan Risiko (Risk Matrix)

\begin{tabular}{|c|c|c|c|c|c|c|}
\hline \multirow{2}{*}{ No } & \multirow{2}{*}{ Sumber hazard } & \multicolumn{3}{|c|}{ Level kriteria } & \multirow{2}{*}{ Warna } & \multirow{2}{*}{ Risk level } \\
\cline { 3 - 5 } & (L) & (C) & (L.C) & & \\
\hline 1 & Sikap pekerja & 5 & 4 & 20 & & Ekstrim \\
\hline 2 & Kondisi lantai & 3 & 2 & 6 & & Risiko sedang \\
\hline 3 & Pengelasan & 3 & 3 & 9 & & Risiko tinggi \\
\hline 4 & $\begin{array}{c}\text { Brander oxy } \\
\text { acetylene }\end{array}$ & 3 & 4 & 12 & & Risiko tinggi \\
\hline 5 & Pembubutan & 3 & 3 & 9 & & Risiko tinggi \\
\hline 6 & $\begin{array}{c}\text { Gerinda (hand } \\
\text { grinding) }\end{array}$ & 2 & 3 & 6 & & Risiko sedang \\
\hline 7 & Mesin gerinda & 2 & 3 & 6 & & Risiko sedang \\
\hline 8 & Jigsaw & 2 & 3 & 6 & & Risiko sedang \\
\hline 9 & Hoistcrane & 2 & 4 & 8 & & Risiko tinggi \\
\hline 10 & Mesin bor & 2 & 3 & 6 & & Risiko sedang \\
\hline
\end{tabular}




\begin{tabular}{|c|c|c|c|c|c|c|}
\hline 11 & Bor (hand bor) & 2 & 3 & 6 & & Risiko sedang \\
\hline 12 & Panel & 1 & 4 & 4 & & Risiko tinggi \\
\hline
\end{tabular}

Risiko bahaya yang ditimbulkan pada area Workshop PDAM Tirta Kncana antara lain sebagai berikut:

a. Risiko ekstrim, yaitu pada sikap pekerja

b. Risiko tinggi, Yaitu pada pengelasan, BOA, pembubutan, hoistcrane, dan panel

c. Risiko rendah, yaitu pada Kondisi lantai, Gerinda tangan, mesin gerinda, jigsaw, bor tangan, dan bor mesin.

Perancangan rekomendasi atau usulan perbaikan dilakukan berdasarkan hazard (potensi bahaya) yang terjadi. Penulis menganalisis dan memberikan rancangan perbaikan hanya untuk sumber bahaya dengan risiko ekstrem dan tinggi. Ini bertujuan agar lebih berfokus pada permasalahan dari sumber bahaya yang dapat mengakibatkan kecelakaan fatal. Dengan adanya usulan perbaikan yang diberikan nanti perusahaan dapat mengurangi tingkat kecelakaan dan mencegah adanya kecelakaan yang serupa lagi dengan sebelumnya. Berikut merupakan analisis kejadian dari sumber bahaya dan usulan perbaikan yang diberikan:

a. Rekomendasi perbaikan pada risiko ekstrem. Rekomendasi perbaikan yang diusulkan oleh penulis untuk menanggulangi potensi bahaya yang disebabkan oleh potensi bahaya (hazard) risiko ekstrem yang tidak memenuhi standard dalam keselamatan kerja dan prosedur kerja yang baik seperti berikut :

1) Berupa jadwal pelatihan K3 tentang penggunaan APD yang akan diselenggarakan oleh pihak manajemen

2) Membuat worksheet dalam penggunaan APD di area kerja supaya para pekerja dapat langsung membaca apa saja potensi bahaya yang akan mereka alami apabila tidak menggunakan APD.

3) Saling mengingatkan para pekerja untuk selalu menggunakan APD

4) Menyediakan APD kepada seluruh karyawan.

b. Rekomendasi perbaikan pada risiko tinggi. Rekomendasi perbaikan yang dapat diusulkan oleh penulis untuk menanggulagi potensi bahaya yang disebabkan oleh potensi bahaya (hazard) dengan risiko tinggi yaitu seperti berikut :

1) Melakukan perawatan rutin terhadap mesin, maupun alat yang terdapat dilingkungan kerja,

2) Melakukan pengawasan pada para pekerja, dan

3) Saling mengingatkan para pekerja untuk selalu menggunakan APD.

\section{KESIMPULAN}

Kesimpulan yang dapat diambil dari penelitian ini berdasarkan rumusan masalah adalah sebagai berikut: Potensi bahaya kecelakaan kerja yang dapat terjadi pada area Workshop PT. PDAM Tirta Kencana Samarinda berasal dari sumber bahaya yang telah digolongkan menjadi 12 sumber, Risiko bahaya yang ditimbulkan pada area Workshop PT. PDAM Tirta Kencana Samarinda 
meliputi risiko ekstrim, risiko tinggi, risiko sedang, dan Rekomendasi yang diberikan kepada perusahaan, berdasarkan sumber risiko bahaya yang ada, meliputi risiko ekstrem dan risiko tinggi. Untuk memperbaiki risiko ekstrem, perlu dibuat prosedur operasional baku untuk keselamatan dan kesehatan kerja (K3) dan memperhatikan penggunaan APD. Untuk memperbaiki risiko tinggi, perlu dilakukan perbaikan sesuai kondisi yang dihadapi.

\section{DAFTAR PUSTAKA}

a. Anizar, 2009, Teknik Kesehatan, Kecelakaan, dan Kerja di Industri, Edisi Pertama, Graha Ilmu, Yogyakarta

b. Baharudin, Zulkifli, A., 2009, Analisis Perawatan Berbasis Keandalan Sistem

Distribusi Minyak Lumas Mesin Utama KMP. Buntoharu, Makassar

c. Buntarto, 2015, Panduan Keselamatan Kesehatan dan Kerja untuk industry, Jakarta.

d. Christina, W.Y., Djakfar, L., dkk. 2012, Pengaruh Budaya Keselamatan dan

Kesehatan Kerja, Universitas Brawijaya, Malang, Vol. 6, N0. 1

e. Darmawi, H., 2016, Manajemen Risiko, PT.Bumi Aksara, Jakarta

f. Efranto, R, Y., Tama, I, P., 2013, Analisis Potensi Bahaya Serta Rekomendasi

Perbaikan Dengan Metode Hazop Melalui Perangkingan OHS Risk Assesment And Control, Malang

g. Juliana, Anda Ivana., 2008, Implementasi Metode Hazop Dalam Proses identifikasi

Bahaya dan Analisa Risiko Pada Feedwater System di Unit pembangkitan Paiton PT. PJB, Surabaya.

h. Munawir, A., 2010, HAZOP, HAZID, VS JSA, Migas Indonesia

i. Ramdan, I,M., 2006, Dasar-Dasar Kesehatan dan Keselamatan Kerja, Edisi Pertama. Universitas Mulawarman, Samarinda

j. $\quad$ Restuputri, D.P., Sari, R.P.D., 2015, Analisis Kecelakaan Kerja Dengan

Menggunakan Metode Hazard and Operability Study (Hazop), Universitas

Muhammadiyah Malang, Malang, Vol. 14, No. 1

k. Retnowati, D., 2017, Analisis Risiko K3 Dengan Pendekatan Hazard And Operability

Study (HAZOP), Surakarta

1. Ridley, J., 2004, Kesehatan dan Keselamatan Kerja, Edisi Ketiga. Erlangga, Jakarta

m. Sucipto, 2012, kesehatan dan Kecelakaan kerja, Jakarta. 
n. Suma'mur, P,K., 2009, Higiene Perusahaan dan Kesehatan Kerja (Hiperkes), CV Sagung Seto, Jakarta

o. UNSW Health and safety, 2008, Risk Management Program Camberra, University Of New South Wales

p. Vimalasari, T., 2016, Hazard And Operability Study (HAZOP) Dan Penentuan Safety Intefrity Level (SIL) Pada Boiler SB-02 PT. SMART Tbk, Surabaya.

q. Widayana, I, G., 2014, Kesehatan Kecelakaan Kerja, Graha ilmu, Yogyakarta 